\title{
Hacia la segmentación significativa
}

\section{Towards significant segmentation}

\author{
José Antonio París (Argentina) \\ Universidad Nacional de La Plata \\ marketing.jose.pari@gmail.com
}

\begin{abstract}
Resumen
La segmentación es uno de los tres pilares del márquetin. Como tal su importancia es vital a la hora en que las entidades y empresas de todo tipo se quieran dirigir a sus respectivos mercados. Ahora, un punto esencial es que las organizaciones no deberían elegir de manera unilateral a sus segmentos de mercado meta. Por el contrario, el proceso, en realidad, se produce justamente al revés. Es decir, son los consumidores quienes se autosegmentan antes de que la organización trabaje en ello. Esto significa que las entidades y empresas deben hacer un esfuerzo mayor por identificar a esos segmentos ya
\end{abstract}

\begin{abstract}
Segmentation is one of the three pillars of marketing. As such its importance is vital when the institutions and enterprises of all kinds want to lead their respective markets. Now, a key point is that organizations should not unilaterally choose their target market segments. On the contrary, the process takes place in reverse. That is, consumers who are self-segmented before the organization works on it. This means that the institutions and companies should make a greater effort to identify those segments already defined, and for this, the methodology traditionally used, founded on the basis of segmentation turns out to be an oversimplification of the problem in question.
\end{abstract}

FECHA DE RECEPCIÓN:

FECHA DE REVISIÓN:

APROBACIÓN:
22 de octubre de 2013 28 de octubre de 2013 29 de octubre de 2013
Para Citar este artículo / to Cite this article

París, J. (2013). Hacia la segmentación significativa. Poliantea, (IX), 17, pp. 1 1-39 
definidos, y para ello la metodología tradicionalmente utilizada, basada en las bases de segmentación, resulta ser una extrema simplificación del problema en cuestión.

Palabras clave: mercado, segmento, significado, segmentación.
Keywords: market segment, meaning, segmentation 


\title{
Hacia la segmentación significativa
}

\section{Towards significant segmentation}

\author{
José Antonio París (Argentina) \\ Universidad Nacional de La Plata \\ marketing.jose.pari@@gmail.com
}

\section{Introducción a la segmentación de mercado}

A pesar de que nos hallamos dedicados al márquetin todo el tiempo, hay aspectos del mercado que aún no nos dejan de sorprender. Como ejemplo, solemos ser usuarios de las grandes superficies minoristas que hemos llamado "hipermercados", no por el placer que estos sitios nos provoquen o por los supuestos que prometen sus anuncios, sino más bien por una cuestión de practicidad y de economía de tiempo. Es más, diríamos que, en general, odiamos a estas grandes superficies; sin embargo, las compras de los bienes de consumo también hay que hacerlas y no queda otra cosa que compartir tan tediosa tarea con nuestras parejas. No obstante, en dichas incursiones a estos antros del consumo masivo solemos tener un momento de cierto placer o, al menos, de no tan tediosa tarea. En nuestro caso, se trata de la búsqueda y selección de vinos. Quienes solemos apreciar los buenos vinos, acostumbramos pasear por las cuantiosas góndolas observando y analizando en detalle las más de seiscientas etiquetas de distintas marcas, variedades y denominaciones de origen que hoy se ofertan de manera muy distinguida, por cierto, de dichos elíxires del placer del buen beber. Pues bien, luego de una prolija selección, a partir de los significados construidos por las ofertas y mensajes de las diversas marcas, etiquetas, cenefas, carteles, formas de botellas y precios adheridos, finalmente elegimos. Y claro está, estamos 
ciertamente convencidos de que hemos hecho una correcta selección, sobre todo, muy original y personalizada, y si se quiere, también especializada; es más, la calificamos como casi única. Pero ¿̇realmente es así? La respuesta es no. No es así, ya que nuestra elección, por más personalizada que parezca, en realidad obedece a un patrón de consumo ligado a un significado levantado desde lo profundo de nuestro inconsciente, o según el caso recientemente generado en el neocórtex (corteza cerebral) por una propuesta o promoción supuestamente inteligente definida por la bodega de la empresa oferente. Y lo peor de todo es que la comprobación de este último argumento está justamente a dos cajas de distancia en el momento de realizar los pagos de los artículos adquiridos. Si con asombro podemos ver a otro señor, que no tiene mucho parecido a nosotros, ni en su aspecto, ni en su forma de vestir, ni siquiera en su comportamiento, sin embargo ha elegido exactamente la misma botella de vino. La respuesta a dicha situación es la siguiente: pareciera que de alguna manera conformamos segmentos de mercados para los distintos significados que promulgan o generan los productos o servicios. Ahora bien, que compartamos un segmento de mercado para determinado producto-significado no significa que tengamos perfiles similares o compartamos las mismas preferencias o conductas de compra para todos los productos o servicios. Y este aspecto es el que no supo interpretar el márquetin tradicional de la escuela angloamericana, y por ende enfocaron sus esfuerzos en definir "perfiles de compradores" o "perfiles de consumidores" que anticipamos no funcionan de dicha manera, ya que un consumidor A puede compartir un segmento con un consumidor $B$ para un determinado producto-significado, pero no necesariamente tenga que compartir otros segmentos y mucho menos todos. Es decir, el segmento de mercado está ligado indisolublemente a un determinado significado, y eso no quiere decir que existan perfiles de consumidores que consuman prácticamente los mismos productos y servicios. A decir verdad, que un consumidor $A$ comparta varios segmentos con un consumidor $\mathrm{B}$ es más una cuestión aleatoria que una tendencia verificable científicamente.

Segmentación es, entonces, desde la óptica del márquetin esencial, 
el término dado al agrupamiento de clientes con significados similares acerca de algún producto o servicio determinado, que sobre las bases de las necesidades y sus deseos generan escalas de preferencias por ellos, por lo cual, se vuelve una parte indispensable del planteo estratégico del márquetin, convirtiéndose en uno de sus tres pilares de base. De ahí que desde nuestro punto de vista la selección de los segmentos de mercados debe ser una decisión estratégica clave de toda la organización y no una simple herramienta táctica o incluso operativa del área de márquetin. Sin embargo, la gran mayoría de los autores más reconocidos o leídos de márquetin insisten en que se trata de un proceso en el que se divide el mercado. Por ejemplo, uno de los libros más utilizados en las universidades estadounidenses y latinoamericanas, Fundamentos de marketing (Stanton, Etzel y Walker, 1999), afirma acerca de la segmentación de mercado, que se trata de un:

[...] proceso que consiste en dividir el mercado total de un bien o servicio en varios grupos más pequeños e internamente más homogéneos. La esencia de la segmentación es que los miembros de cada grupo sean semejantes con respecto a los factores que repercuten en la demanda. Un elemento decisivo del éxito de una compañía es la capacidad de segmentar adecuadamente su mercado.

Pero, como anticipamos, estos autores no son los únicos que afirman que se trata de una proceso de división del mercado, de hecho con una visión más latina los autores Santesmases, Sánchez y Kosiak (2000) en su libro Marketing, conceptos y estrategias, presentan a la segmentación si se quiere de dos maneras distintas. De una de ellas afirman en la introducción general del libro que (Santesmases et al., p. 92): "la segmentación de mercados es el proceso de clasificar grupos de acuerdo con características que son relevantes para el comportamiento de compra o de consumo". Sin embargo, cuando abordan decididamente el capítulo correspondiente sobre segmentación vuelven a insistir en el enfoque clásico (Santesmases et al., p. 213): "la segmentación es un proceso de división del mercado en subgrupos homogéneos, con el fin de llevar a cabo una estrategia comercial diferenciada para cada uno de ellos, que permita satisfacer de forma más efectiva 
sus necesidades y alcanzar los objetivos comerciales de la empresa”. En párrafos posteriores veremos que estamos más de acuerdo con la primera observación respecto de la conceptualización de estos autores con referencia a este tema. También tenemos la obligación de citar al autor que es considerado el padre del márquetin angloamericano, es decir, Philip Kotler (1995), quien se refiere a la segmentación de la siguiente manera:

La segmentación de mercado es el arte de dividir un mercado en grupos diferentes de consumidores que podrían requerir productos o combinaciones de marketing diferentes. La empresa tendrá que identificar diferentes formas de dividir el mercado, desarrollando perfiles y descripciones de los segmentos resultantes.

Otros autores cambian el verbo "dividir" por "subdividir", como es el caso del español E. Ortega en su libro La dirección de marketing (1987):

La segmentación de mercados consiste en la subdivisión del mercado en una serie de grupos o segmentos homogéneos según una o varias variables, mediante diferentes procedimientos estadísticos, a fin de poder aplicar a cada segmento las estrategias más adecuadas a los objetivos de la empresa.

Incluso el Diccionario de términos de mercadotecnia presentado en la página de la American Marketing Association define la segmentación del mercado como "el proceso de subdividir un mercado en subconjuntos distintos de clientes que se comportan de la misma manera o que presentan necesidades similares. Cada subconjunto se puede concebir como un objetivo que se alcanzará con una estrategia distinta de comercialización". Ahora bien, no solo llegan estas definiciones desde el área del márquetin, ya que desde otras encontramos también propuestas similares. Por ejemplo, desde el campo de la investigación de mercados McDaniel y Gates en su libro Investigación de mercados contemporánea (1999, p. 733), afirman: "la segmentación de mercado divide a los consumidores y a los clientes potenciales en subgrupos que presentan distintas sensibilidades ante una o más variables de la mezcla del mercado". Y desde la publicidad O'Guinn, Allen y Semenik en su libro Publicidad y comunicación integral de marca (2004, p. 25) definen: "segmentación del mercado es el proceso de desglosar 
un mercado grande y muy variado (heterogéneo) en submercados, $\mathrm{o}$ segmentos que son más similares en términos de lo que el consumidor busca, o se supone que busca".

Ahora bien, pareciera que la acción de segmentar implica cortar, dividir, subdividir, fraccionar, desglosar, seccionar, partir o clasificar en segmentos al mercado. Por lo cual, debemos decir que creemos que la palabra "segmentación" no es la más feliz para la idea a transmitir, ya que como hemos visto, desde el punto de vista de nuestro márquetin esencial es exactamente lo contrario, pues no se trata de dividir, sino de "agrupar" de alguna manera a los consumidores que tienen el mismo significado en común para determinado producto o servicio. En este sentido, Solomon en su libro Comportamiento del consumidor (2008, p. 6) anticipa:

El uso de estrategias de segmentación de mercado implica dirigir una marca solo a grupos específicos de consumidores y no a todas las personas, incluso eso significa que otros consumidores que no pertenecen a este mercado meta no se sientan atraídos hacia ese producto.
Por lo cual, un punto en el que todos coincidimos es que se trata de direccionarse a un grupo o varios de consumidores, dejando de lado a otros, aunque la gran mayoría de los autores insisten en definir a la segmentación de mercado como el proceso de dividir un mercado en segmentos más homogéneos, es decir, dividirlo en grupos uniformes más pequeños que tengan características y necesidades semejantes. Pero, como es de esperarse, desde nuestro enfoque esencial esto es una aberración, por dos motivos; primero, el mercado actúa como un cuerpo indivisible por el solo hecho de que si a un mercado le sacamos una parte componente de él, y de manera total, ese mercado no solo se ve alterado, sino que deja de actuar como lo venía haciendo; por lo que el mercado se debe respetar como un todo indivisible; y en segundo término, la segmentación es un proceso si se quiere inverso, ya que en realidad es de agrupamiento, más que de división. En este sentido, no somos los únicos en afirmar esto; por ejemplo, desde el campo de la administración Hitt, Ireland y Hoskisson en su libro Administración estratégica (2004) afirman: "Este proceso consiste en segmentar el mercado, es 
decir, agrupar a las personas que tienen necesidades parecidas, en grupos particulares e identificables". Quienes también comulgan con estas ideas son los especialistas y profesionales del márquetin de relaciones, del márquetin uno por uno y de las bases de datos (CRM), como es el caso de los autores González, Sánchez y Salutregui en su libro Personalización (2004), en el cual afirman que la segmentación fina es necesaria y básica para la personalización de la cartera de clientes, ya que en estos casos los esfuerzos para lograr una segmentación precisa, o de granularidad de calibres pequeños (luego de un prolijo tamizado o zarandeo del mercado), son para estas tendencias de mercadeo casi siempre considerables, implicando recursos de todo tipo, tanto en las fases de definición del mercado meta (target) como en los momentos de crecimiento y mantenimiento de la vida de los segmentos. Algunos autores han llamado a este punto de vista "contrasegmentación", es decir, visualizan el agrupamiento como un proceso, si se quiere opuesto, al de la segmentación. Nombre con el que no estamos de acuerdo, ya que no se trata de ir en contra de nada, sino de perfeccionar el proceso de segmentación, además de que este término lleva a confundir al mercadólogo. Desde nuestro punto de vista se trata del mismo concepto tratado desde distintos puntos de vista, pero en lo que se refiere a segmentación significativa se incorporan elementos esenciales al sistema de análisis.

Desde otro punto de vista, cuando las personas se radican en determinados barrios de la ciudad o se asocian a determinados clubes sociales se están agrupando entre sí y de manera natural, es decir, sin la intervención de ningún mercadólogo o marquetinero. En definitiva estos segmentos son grupos más homogéneos en cuanto a su estilo de vida aunque no necesariamente en lo que se refiere a su cultura (por ejemplo, las personas en un segmento son similares en sus actitudes sobre ciertas variables mercadológicas, incluso sin saberlo). Debido a esta similitud dentro de cada grupo, es probable que respondan de modo similar a determinadas estrategias y tácticas de márquetin. Es decir, los integrantes de este segmento por poseer algunos significados similares con respecto a determinado producto o servicio, probablemente tendrán las mismas reacciones 
acerca de la aplicación de un plan de márquetin o del márquetin mix de un determinado producto diseñado y producido de un modo particular, vendido a determinado precio, distribuido de determinada manera y promocionado mediante una forma dada. A pesar de esta argumentación hemos decidido no tratar de alterar el nombre del concepto segmentación, porque en definitiva lo que se dice, en realidad, no es lo que se hace. Admitiendo esta situación semántica algo contradictoria, seguiremos refiriéndonos a este poderoso pilar del márquetin como segmentación de los mercados, aunque nos distinguiremos de alguna manera con un apelativo aclaratorio que busca marcar la diferencia en cuanto a la profundidad y rigor del tamizado con que se realizará el proceso y, por lo cual lo hemos denominado proceso de segmentación significativa.

Philip Kotler (1989, p. 34) define un segmento de mercado como "consumidores que respondan de una manera similar a un conjunto dado de estímulos de mercadotecnia". Como se aprecia, esta definición no solo carece de sustancia, sino que no induce a ver el segmento como un subconjunto del mercado con características homogéneas. Además, si se dieran las condiciones para que varios consumidores pertenecientes a distintos segmentos respondan ante determinados estímulos de márquetin de la misma manera, estos consumidores podrían, sin embargo, no pertenecer al mismo segmento de mercado, razón por la que descartamos esta anterior definición, ya que es fácilmente falseable y no llega a la esencia del problema, ni siquiera abarca todos los aspectos de forma del concepto segmentación. Este concepto trata de ver a un mercado heterogéneo como una serie de pequeños mercados homogéneos. Por lo tanto, el primer paso en el proceso de segmentación consiste en responder: ¿qué segmentos del mercado lo conforman? Responder este interrogante es crucial para poder dirigirse a los segmentos y luego abordarlos con éxito (es decir, determinar en qué mercados se quiere competir). Para ello muchos autores han recurrido a la teoría que se apuntala a través de las bases o variables de segmentación, las que según ellos actuarían como una especie de filtros (pasa - no pasa) del mercado, pero hay que decir también que en algo sí coincidimos con Kotler, en que no 
hay una sola y única manera de segmentar, por lo tanto no podemos referirnos a una única metodología. De hecho en este artículo introduciremos una metodología que si bien utiliza en una primera etapa parte la metodología tradicional, luego esta es complementada con una segunda etapa de segmentación. Esta última se basará en una aplicación metodológica totalmente innovadora en su conformación, usando para ello herramientas que si bien son preexistentes y reconocidas, también son combinadas y aplicadas de una forma totalmente nueva, pero adquieren el grado de universales, ya que son aplicables a todo tipo de mercado-producto o mercado-servicio, y que como ya hemos dicho, denominaremos segmentación significativa.

\section{¿Qué es la segmentación de mercado?}

Cuando hablamos de "mercado", nos referimos a una población económicamente activa o pasiva conformada por grupos de consumidores organizacionales o finales (personas físicas) que tienen distintas necesidades, gustos, personalidades, culturas, además de diferente poder adquisitivo. Lo cual define de ellas ciertas preferencias de consumo que, como sabemos, es el motivo fundamental del estudio del comportamiento del consumidor y del márquetin en general. Ahora, cuando hablamos de "segmentación de mercados" nos referimos a la acción de detectar y segmentar (agrupar o clasificar distintos grupos de consumidores con características de consumo bastante similares u homogéneas). A estas personas físicas u organizaciones las definimos como consumidores finales y consumidores organizacionales respectivamente. Cuando dichos consumidores se agrupan distintivamente conforman segmentos, cuya principal característica es que tienen pautas de consumo similares para un determinado significadoproducto o significado-servicio.

A esta altura vale la pena reconocer que fue Wendell R. Smith quien conceptualizó e implementó el término "segmentación de mercado" por primera vez en 1956, en el Journal of Marketing; este autor pone en duda las teorías económicas de los años treinta (clásica y neoclásica) que asumen las ideas de mercados perfectos con ofertas y demandas homogéneas. Además, según Smith: 
Las estrategias de segmentación y diferenciación pueden ser empleadas simultáneamente, pero más comúnmente se aplican en secuencia, en respuesta a las condiciones cambiantes del mercado. En cierto sentido, la segmentación es un fenómeno momentáneo o de corto plazo en que el uso efectivo de esta estrategia puede conducir a un mayor reconocimiento formal de la realidad de los segmentos de mercado a través de la redefinición de los segmentos como los mercados individuales. La redefinición puede resultar en un retroceso a la diferenciación (Smith, Wendell R. [julio de 1956]. Product Differentiation and Market Segmentation as Alternative Marketing Strategies. Journal of Marketing 21(1), 3-8.

Se aprecia que para segmentar las empresas también deben diferenciar sus productos, lo cual, desde luego que fue un avance más que significativo para el márquetin de la década de los cincuenta. De este autor se ha pasado por alto un aspecto no menos importante: como se aprecia en la anterior cita, él además habla de la temporalidad de los segmentos, dando a entender que los consumidores están en permanente mudanza de gustos o preferencias.

Según Smith, también es un hecho real que debe existir tanto la diversidad en la demanda como en la oferta; esto es algo sorprendente, porque para defender la necesidad de segmentar, argumenta, hay que sostener la heterogeneidad de la oferta a causa de las diferencias entre las empresas por sus distintos procesos, producción, tecnologías, capacidades, competencias, suministros, diseño, etc. Continúa afirmando que aunque no lo parezca, la diversidad en la oferta es importante, ya que es una primera argumentación para defender diversas maneras de segmentar, según si el producto tiende a ser un commodity o un producto altamente diferenciado (con mucho valor agregado). Es así como se explica la existencia de la diferenciación (del producto) por la existencia de su correspondiente segmento. Es decir, un concepto implica al otro, y por lo tanto, lo convalida. El creador del término "segmentación" acaba argumentando la importancia de la segmentación por la tendencia a una preeminencia del consumidor y la riqueza que puede dar el hecho de aplicar nuevas técnicas y metodologías científicas a fin de solucionar problemas de enfoque de márquetin. Pues bien, en definitiva lo que se trata de hacer con la segmentación de mercado es encontrar "el punto de enfoque", en el cual se pondrá 
todo el esfuerzo del proyecto, se centrarán todas nuestras acciones estratégicas y las políticas de márquetin enfocadas en dichos segmentos. La segmentación de mercado, según el creador del concepto, implica visualizar un mercado heterogéneo conformado por un número de mercados más homogéneos, más pequeños, en respuesta a diferencias o preferencias atribuibles a los deseos de los clientes que buscan saciarlas y satisfacerse con productos o servicios que se ajusten más a los significados alojados en sus mentes y que actúan como nexos con los otros de acuerdo a los requerimientos demandados y también los ofrecidos.

Básicamente la segmentación de mercado, valga la redundancia, "segmenta" a una gran masa de consumidores en un grupo reducido tras la congregación de los elementos similares que la componen. De estos segmentos es que la empresa se nutre, de sus clientes potenciales (sobre los que hará foco), que en definitiva es lo que más interesa desde el punto de vista del negocio.

Pero aunque este concepto de segmentación ha sido ampliamente aceptado por la "comunidad marquetinera", que no dudó en darle el apelativo de "pilar del márquetin", aún sigue presentando un interrogante esencial, en cuanto qué tan bien describe la situación mercadológica de un producto o servicio en particular y qué elementos de juicio aporta a la relación significadoproducto o significado-servicio. Es decir, todavía no podemos hablar de una metodología científica de la segmentación, es más, ni siquiera estamos seguros de si sus aportes empíricos obedecen a una regla permanente, de ahí que nuestro desafío en esta materia será identificar nuevamente los argumentos esenciales o de base para desarrollar una metodología cuyo nivel de precisión y ajuste sea el requisito básico.

A decir verdad, la literatura especializada que aborda esta temática no abunda, y lo que hay en realidad es una interminable repetición de la metodología de segmentación sobre la definición de bases preconcebidas por los mercadólogos desde finales de la década de los cincuenta. Es más, la literatura académica le dedica considerable atención a los aspectos de la investigación del mercado asociados con la segmentación, a nivel táctico-operativo, pero no profundiza en los aspectos esenciales y estratégicos del 
concepto en cuestión, temas todos que de alguna manera no solo trataremos de presentar, sino de resolver con nuestra metodología. Incluso, por el aporte de algunos autores de comportamiento del consumidor $y$ fundamentalmente de los mercadólogos se ha llegado a interpretar que la segmentación es una herramienta de la investigación de mercados a partir de instrumentos técnicos y estadísticos definidos para manejar una herramienta práctica, aunque quizás poco eficaz para realizar la tarea encomendada de manera operacional. En este sentido, siguiendo el cuarto libro del Ensayo sobre el entendimiento humano de John Locke (1998), quien trataba de averiguar lo que se establece a partir del conocimiento humano que se basa en las definiciones que da a las cosas llamadas "reales", el saber humano es limitado.

Según Locke, solo el conocimiento proporcionado por los sentidos puede indicar lo que de realidad hay en los objetos del mundo. La verdad es cuestión solo de palabras, mientras que la realidad interesa a los sentidos. Y a falta de algo mejor, para paliar la limitación de las posibilidades cognoscitivas de la realidad se puede intentar utilizar en un discurso la noción de cosas "probables", es decir, la metodología utilizada hasta el momento para la segmentación ofrece una herramienta táctica-operativa que permite de alguna manera tratar de acercarnos al mercado meta de la organización, aunque de hecho no genera un camino o no conforma parte de la estrategia organizacional como debería serlo. Pero, como hemos afirmado y repetimos nuevamente en este párrafo, la segmentación conforma una parte importante de la estrategia organizacional y no puede ser limitada a identificar y referirse a una simple condición del mercado cuya asignación numérica puede distar significativamente de su dimensión cuantitativa real, por lo cual estos aspectos deben ser abordados desde lo empírico y con la mayor argumentación científica posible, dada la importancia de dicho proceso.

Y para ello recurriremos al apoyo de todas las ciencias y disciplinas de las que se nutre el márquetin: filosofía, semiología, antropología, sociología, psicología, neurociencia y administración, a los fines de lograr una metodología de segmentación universal y conceptual que permita desde la heurística el acercamiento 
final de la organización a su mercado meta.

\section{El proceso de segmentación de mercados: justificación final}

Hemos dicho que el nivel de complejidad de los mercados ha ido en aumento exponencial en las últimas décadas, a tal punto ha llegado su heterogeneidad de acuerdo con las distintas tendencias que incluso nos conducen en la actualidad al concepto de segmento de a uno. Por lo que, hoy, la segmentación ya no está en discusión, ya que las condiciones de márquetin con o sin segmentación pueden variar dramáticamente, tal cual se puede apreciar en la figura 1.

Figura 1. Condiciones de márquetin, con o sin segmentación

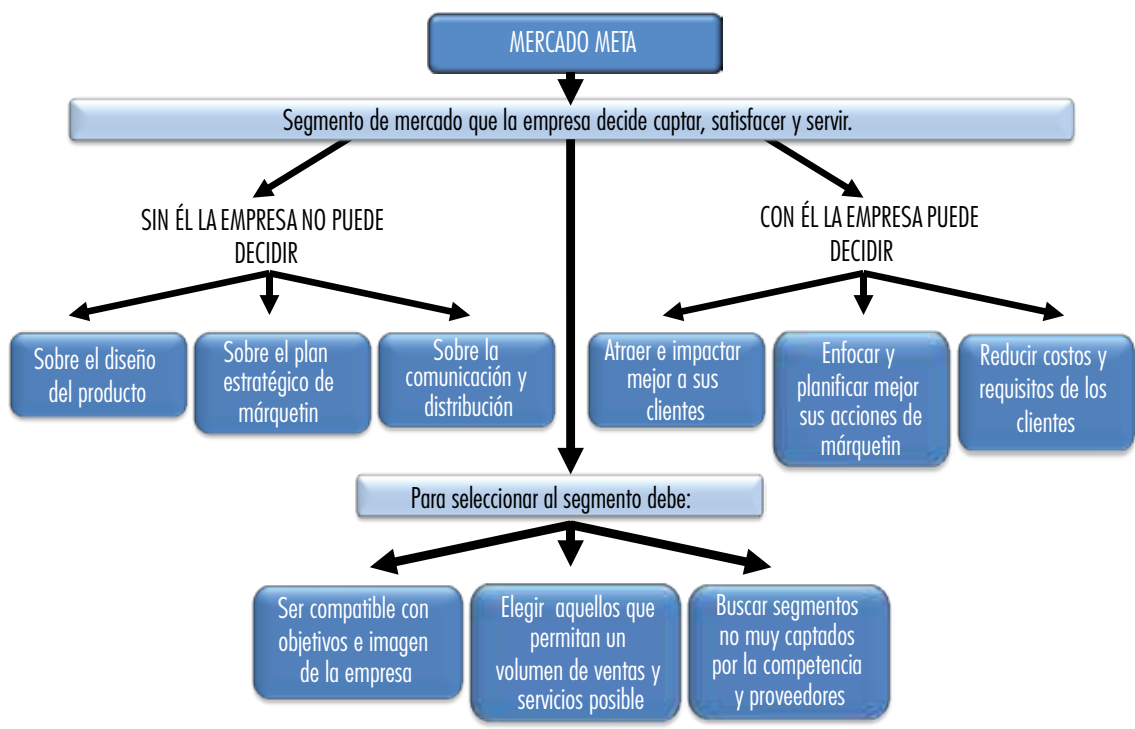

Esta es la razón por lo que actualmente la segmentación como proceso es vital para el márquetin y uno de sus principales pilares sobre los que se sustenta.

En esta figura también se anticipa que al margen del proceso de segmentación la selección del segmento o segmentos para conformar el mercado meta dependerá de tres factores a tener muy en cuenta: los objetivos y la imagen institucional de la empresa u organización, el volumen potencial de impactos 
institucionales (ventas u otros) y el grado de satisfacción de dicho segmento generado por otros competidores o prestadores del mercado.

\section{Beneficios de la segmentación}

La teoría de la administración como técnica-científica dedicada al desarrollo y manejo de organizaciones sugiere dos enfoques: uno endógeno y otro exógeno. En el primero la organización se ocupa principalmente de tener bien en claro qué es lo que mueve a la organización, cuáles son las aspiraciones de sus líderes, porque en definitiva una empresa, entidad gubernamental o no gubernamental, es una organización de personas, cuyos directivos y personal definen buena parte de su destino con las decisiones que toman, con las acciones que emprenden y como compiten con los otros oferentes, siempre a partir de sus habilidades acumuladas. Pero claro está, en este enfoque endógeno también influyen sus capacidades, de manera tal que infraestructura, recursos, equipamientos, instrumentos, know how (patentes), materiales e insumos también participan en la gestión de las tan deseadas capacidades estratégicas de la organización y de su esencia competitiva (core competence), para poder determinar cuál será la estrategia posible de dicha organización en el mercado, es decir, aquello que sí pueden hacer para captar mercados y generar riqueza.

Ahora, desde el otro enfoque, el exógeno, el de las restricciones y las oportunidades del negocio, es que se diseña la estrategia ideal, a la que deberá aspirar la organización desde su estrategia posible para acortar la diferencia que la separa de la estrategia ideal (gap), a los fines de aprovechar de la mejor manera las condiciones ofrecidas por el entorno en dicho momento y en el futuro. Desde este enfoque es que las organizaciones buscarán a partir de las condiciones externas una ventaja competitiva sostenible y defendible, tanto a corto como a largo plazo. Bajo este enfoque la segmentación de mercado normalmente se considera formando parte de una metodología práctica que visualiza al mercado como "lo que está afuera" de la organización y habrá que atender de alguna manera. Y para esto los segmentos son considerados el resultado de un "sistema de filtrado mercadológico", pero sin aportar demasiados argumentos teóricos en su sustentación, es decir, sin conocer 
los motivos o las razones esenciales del porqué hacen lo que hacen los consumidores.

De vuelta se trabaja con las consecuencias de los ¿para qué?, en lugar de ir a las causas de los ¿por qué? Por lo tanto, entendemos que el segmento se debe "descubrir" y ser interpretado por el investigador con el rigor científico que se requiere. Esta cia del márquetin. (Ver figura 2). perspectiva heurística es necesaria si queremos obtener la información para la toma de decisiones con un alto grado de eficacia, y así dejar de lado la aleatoriedad del márquetin clásico. Entender la relación significado-producto-segmento o significado-servicio-segmento se vuelve entonces esencial para lograr la ansiada efica-

Figura 2. Relación significado-producto-segmento

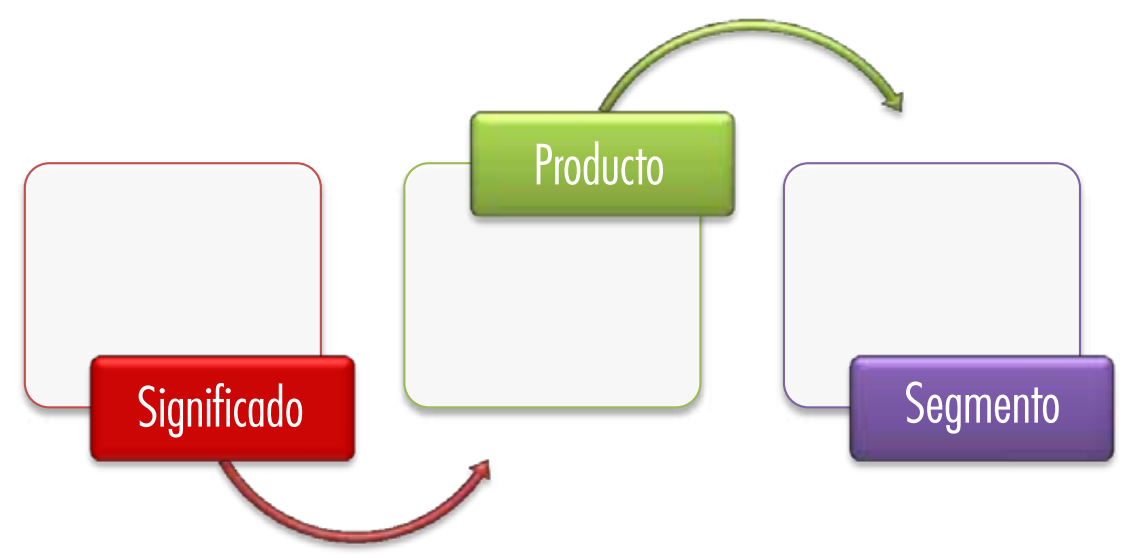

A partir de la segmentación que así fuese creada, la organización puede recibir los siguientes beneficios de su aplicación efectiva:

- Identificar las necesidades más específicas para los submercados.

- Focalizar mejor la estrategia de márquetin. 
no tenga competencia directa o no esté muy interesada en dichos nichos.

- Aumentar las posibilidades de crecer rápidamente en segmentos del mercado sin competidores o con competidores no tan agresivos o poderosos.

\section{Características que debe manejar el proceso de segmentación significativa para convertirse en una metodología más eficaz}

La gran mayoría de la literatura existente y en casi todas las consultoras en las que se realiza segmentación, se opera con la misma metodología basada en la utilización de las variables o bases de segmentación. Ahora, como sabemos, las variables o bases de segmentación usadas como verdaderos "filtros" del mercado es una de las metodologías de segmentación, pero como veremos, no es la única, ni la más exacta, ni tampoco la más completa, ya que hay muchas maneras de segmentar el mercado y no todas tienen el mismo nivel de efectividad. Sin embargo, en términos de utilidad y practicidad los segmentos de mercado deben presentar las siguientes once características comunes, si es que se quiere trabajar eficazmente:
- Diferenciabilidad: los segmentos deberán ser diferenciables entre sí, fundamentalmente en cuanto a sus resultados, más que por sus características intrínsecas $\mathrm{u}$ aspectos formales, como: color de piel, altura promedio, lengua materna, orientación sexual, nacionalidad, etcétera.

- Mensurabilidad: se deberán detectar las variables que pueden medir el poder adquisitivo, la cantidad de personas y el perfil de quienes componen cada segmento para buscar la mejor manera de relacionarlas entre sí. Es decir, hay que evaluar las unidades de medida más idóneas para luego crear los indicadores de seguimiento de dicho segmento.

- Comparabilidad: los indicadores creados según el punto anterior, a su vez pueden ser utilizados en todos los segmentos detectados y a los cuales se dirige la empresa para comparar su potencial y volumen de operaciones reales de cada unos de ellos y de manera comparativa entre sí, de tal manera que se facilite el proceso de toma de decisiones. 
- Accesibilidad: la firma que pretenda abordar dicho segmento deberá tener en cuenta que este constituya una porción del mercado al que pueda acceder a través del uso de una comunicación dirigida a él, ya que muchos segmentos se encuentran tan dispersos que resulta prácticamente imposible abordarlos, por lo menos de manera económica.

- Capacidad de abordaje: la firma deberá evaluar que el segmento en cuestión se pueda atender y alcanzar de manera eficaz, eficiente y efectiva, es decir, de manera competitiva frente a otros potenciales interesados en él, por lo cual deberá tener los recursos, medios e información pertinente para dicho desafío.

- Rentabilidad: los segmentos del mercado a los que pretenda dirigirse la firma deberán ser fundamentalmente rentables, es decir, serán potencialmente generadores de riqueza por medio de los beneficios económicos que generen.

- Singularidad: a los fines de perfeccionar el segmento la firma deberá propiciar un sistema de identificación eficaz que permita perfeccionar dicho segmento, a partir de la detección, cambio o eliminación de elementos que no lo integren realmente por ser singularidades que estén fuera de los lineamientos de dicho segmento.

- Significatividad: para poder dirigirse a dichos mercados y tener éxito en la gestión comercial la firma deberá interpretar con claridad los significados de base en la "mente de dicho segmento". De lo contrario regirán el azar y la aleatoriedad.

- Direccionalidad: la firma deberá diseñar y planificar los lineamientos estratégicos y tácticos que permitan abordar dicho segmento, siempre sobre las bases de sus significados, a los fines de aumentar significativamente su potencial de éxito.

- Practicabilidad: se deberán diseñar programas tácticos y operativos efectivos para atraer a los consumidores y lograr así los objetivos definidos en el punto anterior. Asimismo, realizar un monitoreo/ajuste permanente.

- Universabilidad: quizás sea este el aspecto que le dé 
características científicas al proceso de segmentación, ya que debería ser repetible en todo sitio y todo momento, pero fundamentalmente practicable de manera directa y sin tener que acudir a artilugios de ningún tipo.

\section{Requisitos que debe presentar un segmento de mercado}

Los requisitos que debe presentar un segmento, para ser considerado como tal, son los siguientes:

- Identificable y medible. Este es el requisito básico para que un segmento sea interpretado como tal. Desde nuestro enfoque del márquetin esencial, un segmento implica un producto o servicio, que a su vez está relacionado con un significado. Es decir, el significado es la clave para la determinación del segmento, por lo tanto todos los integrantes del segmento deberán tener en su mente un significado similar del producto o servicio. El otro aspecto de este punto habla de la posibilidad que el segmento debe ofrecer en cuanto a su grado de mensurabilidad, ya que de esta posibilidad dependerá si la empresa decide o no abordar dicho segmento, ya sea por su tamaño o por su rentabilidad potencial.

- Homogeneidad en el segmento. El éxito de un plan de márquetin depende fundamentalmente de este importante aspecto, de ahí que en ningún caso debe ser tomado a la ligera. Una vez identificado el segmento, deberá ser dimensionado acudiendo al apoyo de la estadística, pero este último dato deberá ser ajustado luego de haber realizado una depuración del segmento, ajuste que se refiere a la eliminación de cualquier singularidad que por diversos motivos haya pasado los filtros iniciales. Una singularidad es aquel consumidor final $\mathrm{u}$ organizacional tomado inicialmente como parte de un segmento, pero que aunque mantiene la mayoría de características que lo definen como integrante del segmento, posee alguna característica que lo sacan del conjunto, porque de hecho para esta singularidad el significado será distinto del de los demás, ejemplos: 
pertenece a una cultura diferente, ser practicante de una religión particular, poseer un estado emocional alterado, entre otras posibilidades.

- Estabilidad del segmento. Si bien sabemos que los mercados son esencialmente dinámicos, para que un segmento sea considerado como tal, desde nuestra óptica, este deberá ser lo más estable posible en cuanto a su significado de base. Este atributo, el del significado en la mente del consumidor, es decir, la representación psíquica de la cosa, como requiere de identificación, interpretación, memorización y mantenimiento en la mente tiene un grado de estabilidad más alto que todo lo que sucede fuera de la mente de las personas, que como sabemos está mucho más sujeto al cambio, justamente para tratar de hallar un espacio en la mente del consumidor.

- Sustentabilidad del segmento. El fenómeno de "sustentabilidad" habla de una cierta responsabilidad hacia el futuro de la organización vinculada con el segmento. Según el Diccionario de la lengua española, podemos interpretar este término de manera similar a "sostenible", es decir, desarrollo que, cubriendo las necesidades del presente, preserva la posibilidad de que la organización futura pueda alcanzar sus objetivos con él. Aplicando este concepto al segmento, este debe permitir a la organización que lo aborde poderse proyectar sobre él y ser considerado en su estrategia organizacional tanto en el presente como en un escenario futuro. O sea que aquellos grupos de consumo que se agotan rápidamente no pueden ser considerados sustentables, debido a su limitada capacidad de recuperación, mantenimiento e incluso crecimiento en la escala del consumo del segmento.

- Tamaño acorde con los intereses y capacidades de la organización. El tamaño del segmento debe ser tal que su magnitud se ajuste a los objetivos de la organización, es decir, se debe alinear con su estrategia. A su vez, la organización deberá tener las capacidades organizacionales para poder abordarlo con éxito. 


\section{Niveles de segmentación según su tamaño}

El tamaño del segmento define en parte y de alguna manera la estrategia para poder abordarlo con éxito, por lo cual distinguiremos cuatro categorías, como se puede apreciar a continuación:

- Segmentos de mercado: del total del mercado, es el grupo más amplio en el que podemos ubicar a los consumidores potenciales. Es decir, del total de las personas o empresas, se selecciona un grupo extenso que creemos puede tener los mismos significados de base, deseos similares, necesidades y características parecidas. Si encontramos un gran número de consumidores que tienen un significado inactivo, deseo sin cubrir o aun una necesidad aún no satisfecha, a esto se lo conoce como "segmento virgen", ejemplo: las personas que consumen "productos dietéticos" o los llamados "productos eclécticos", pueden constituir a futuro un segmento significativo del mercado. También podemos ejemplificar el caso de las personas que realizan coleccionismo, como los anticuarios, numismáticos y filatélicos, entre otros; las Van familiares, para 5-7 personas, buscan satisfacer a los segmentos con más de 3-4 hijos, o familias con abuelos en casa.

- Nichos de mercado: es solo una parte del segmento, un grupo específico dentro de un segmento. Sin embargo, este nicho puede ser muy atractivo para pequeñas o medianas empresas que lo puedan abordar, logrando en muchos casos con ellos una importante rentabilidad que compensa el menor volumen de las ventas. Como ejemplo, un nicho de mercado está constituido por los consumidores de "productos orgánicos" o los "productos de alta gama”. También está el caso de los consumos especializados, por ejemplo, dentro del coleccionismo el negocio de la filatelia requiere de coleccionistas de sellos postales o estampillas, llamados filatélicos. La firma alemana BMW realiza producciones de nicho para algunos mercados muy limitados, como es el de los Emiratos Árabes. 
- Micronichos o células de mercado: es aún más pequeño que un nicho de mercado, corresponde a un grupo muy específico dentro de un segmento. Es un punto muy potente de foco para la firma que se dirige a él, pero a la vez cuenta con la desventaja de ser diminuto, comparado con un segmento (y la pérdida de algunos de sus clientes puede hacer tambalear al negocio). Para muchos productos o servicios de alta gama o extremadamente caros se deben buscar estas células de mercado, prácticamente personalizados, a los fines de acelerar el proceso de compra. Como ejemplo, están los consumidores de complementos alimentarios, que además los consumen por problemas de salud. También está el caso de los consumos altamente especializados; por ejemplo, en el negocio de la filatelia hay coleccionistas especializados en estampillas clásicas de 1850 a 1899, con sellos muy particulares, que están dispuestos a pagar verdaderas fortunas por ellas; las firmas automotrices ligadas al lujo, como Rolls-Royce, producen ediciones limitadas para un grupo de consumidores hiperespecializados o un mercado muy exclusivo.

- Segmento de a uno: el acceso a la computadora nos dio la posibilidad de trabajar con el fichero electrónico y en este último las bases de datos adquirieron un formidable valor. Pero una base de datos es mucho más que una simple fuente práctica de información, en realidad se puede convertir en una potente fuente de generación de riqueza. La tecnología informática, las bases de datos electrónicas, las redes sociales y en general las TIC (tecnologías de la información y la comunicación) permitieron la toma de datos de a uno y de esa manera identificar perfiles de necesidades, deseos y preferencias de cada persona. La computadora como soporte inteligente de las bases de datos permite dos cosas: primero, toda la información se puede almacenar de manera electrónica, es decir, libre de papeles ( $p a$ per less); y segundo, a partir de los datos almacenados se puede buscar de modo automático 
entre toda la información con solo el cumplimiento de ciertos criterios de búsqueda, porque los sistemas tipo CRM (customer relationship managemet) toman las características individuales de los consumidores, tales como el sexo, la edad, la ocupación, los ingresos, sus intereses, gustos, preferencias, así como su nivel de estudios, o si es propietario, entre otros tantos datos.

El sistema pondera y califica, para luego asignarle una calificación como cliente potencial, o si lo es, para ponerlo en el nivel que le corresponde de acuerdo con la jerarquía creada para tal sentido. Con esta capacidad la empresa puede realizar una oferta de productos más cercana a los intereses del cliente, y le puede asignar un riesgo, lo que luego se traduce en un determinado nivel de crédito asignado por la empresa para cada uno de sus clientes. A esta política de atención personalizada y especializada en cada cliente el márquetin la denominó "márquetin uno por uno".

Pero debemos advertir que esta política de márquetin llevada a cabo a través de sistemas y software especializados y a la cual podemos calificar de "personalizada", es también deshumanizada (dehumanized or human less), y este aspecto se ha hecho sentir en la cartera de clientes, muchos de los cuales se han desencantado por la falta de contacto humano. Es por esta razón que su puesta en práctica fue muy exitosa en algunos casos, pero no para todos; por ejemplo, en algunos eventos gastronómicos que se realizan en varios sitios del mundo para "paladares hiperespecializados", como en el banquete del emperador chino. Incluso varios correos del mundo han impreso estampillas personalizadas siguiendo la política del márquetin uno por uno. Se hace lo mismo con las ediciones limitadas de algunos vehículos personalizados, como los de Ferrari amarillo con toques personales.

\section{Segmentación en mercados internacionales: ¿puede haber segmentos globales?}

Los mercadólogos de las empresas multinacionales, transnacionales $y$ globales bien quisieran que se pudieran detectar segmentos globales, si los hubiere. Esta situación facilitaría enormemente su función y el márquetin de este tipo de firmas 
internacionales, y además de más fácil sería notablemente más económico. Sin embargo, la verdad dista mucho de esta situación, incluso a pesar de los enormes esfuerzos comunicacionales y miles de millones de dólares que han invertido o gastado grandes compañías internacionales para lograr el tan ansiado homo globalis o consumidor global. Una prueba de su fracaso es que del famoso eslogan afirmando que había que tener la mente abierta o el open your mind del posmodernismo promovido por las economías neoliberales y globalizantes de estas compañías, hoy promueven un eslogan muy diferente, es decir, avisan que hay que actuar localmente, pero ya ir pensando globalmente (en inglés: act local, think global). (Ver figura 3).

Este cambio de política comunicacional fue anticipada por el autor y politólogo, ex asesor presidencial y profesor de ciencias políticas estadounidense Samuel Phillips Huntington en su libro El choque de civilizaciones (2005), quien predijo que la aldea global (mundo global) estaba aún muy lejos de ser una realidad, al afirmar: "el choque de civilizaciones dominará la política a escala mundial; las líneas divisorias entre las civilizaciones serán los frentes de batalla del futuro".

Figura 3. Eslóganes de globalidad

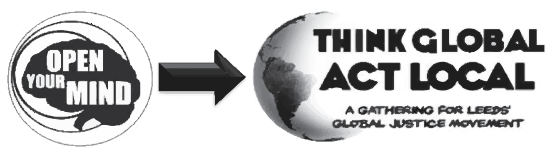

Tomado de: hitp://www.healthyplace.com/blogs/ recoveringfrommentalillness/ 2012/04/mentalillness-stereotypes-and-stigma/open-your-mind-logo-3 / http://www.leedstidal.org/wordpress/initiatives/ past-initiatives/

De hecho, frente a la presión del neoliberalismo y de las compañías internacionales pronto llegaron las disconformidades y la falta de identificación de muchos, que a veces reaccionaron de manera pasiva y resignada, y otras de forma tumultuosa y hasta revolucionaria. Ya sea desde su más profunda identidad cultural, étnica, nacional, lingüística, religiosa y hasta con niveles de fanatismo, como hacía mucho que no se veía en el mundo, sin duda opusieron resistencia al alud mediático que bajaba desde el Norte con un poder nunca antes visto para imponer el enfoque reduccionista del modelo universalista.

Esta situación, casi de confrontación de valores, termina por generar un choque cultural, tal cual lo afirma Samuel Phillips Huntington, 
quien afirma que como verdadero ardid del mundo capitalista occidental los actores políticos principales del siglo XXI serían las civilizaciones. $\mathrm{Y}$ que los principales conflictos serían aquellos entre las distintas culturas y sus civilizaciones (no entre ideologías, como durante la mayor parte del siglo XX, ni entre Estados, como se dio en varias situaciones también a fines del siglo XX, como el conflicto serbiobosnio); serán entonces las culturas y sus diferentes civilizaciones la fuente de conflicto del futuro. Según este autor, las líneas de fractura entre civilizaciones son casi todas religiosas, y hoy se pueden destacar las siguientes diez:

- Cultura occidental: incluye Europa, Norteamérica, Australia y Nueva Zelandia.

- El mundo ortodoxo de Europa oriental y Rusia.

- El mundo latinoamericano de Sudamérica, Centroamérica, México y el Caribe.

- El mundo musulmán del Oriente Medio y el Islam.

- El pueblo judío, la civilización hebrea y la diáspora.

- La civilización hindú, localizada fundamentalmente en la India.
- La civilización sínica de China, Vietnam, Singapur, Taiwán y Corea.

- La civilización japonesa.

- El África subsahariana.

- Las áreas budistas del norte de la India, el Tíbet y el sur de China.

Huntington también arguye que el nivel de crecimiento de Asia oriental hará de la civilización sínica un poderoso rival de Occidente, de la misma manera que el islam ya representa hoy el principal conflicto de Occidente. También establece que el crecimiento demográfico y económico de otras civilizaciones resultará en un sistema de civilizaciones mucho más multipolar que el que existe actualmente. El autor argumenta que el crecimiento de nociones como la democracia o el libre comercio desde el fin de la Guerra Fría solo ha afectado realmente a la cristiandad occidental, mientras que el resto del mundo ha intervenido escasamente en este proceso. Por otro lado, afirma que los conflictos entre civilizaciones son inevitables, puesto que cada una cuenta con sistemas de valores significativamente distintos y por lo tanto con intereses diferentes. En este "nuevo orden mundial" las grandes divisiones de 
la humanidad y los conflictos actuales, más los que surjan en las primeras décadas del siglo XXI, no serían, aunque parezca mentira, de tipo económico, ni geopolítico, ni siquiera ideológico, sino ante todo cultural. Así, Samuel Huntington, al tiempo que presenta un futuro lleno de conflictos, gobernado por unas relaciones internacionales abiertamente "desoccidentalizadas", acaba recomendando un más sólido conocimiento de las civilizaciones no occidentales, con el fin, paradójico, de potenciar al máximo la influencia occidental sobre estas.

Ahora, desde nuestra óptica "latinoamericanicista" no deja de sorprendernos que Huntington considere a la "civilización latinoamericana" como una región distinta de la occidental, lo cual suele chocar con el punto de vista de muchos de los países con gran ascendiente europeo, como Argentina, Chile y Uruguay. Pero, por otro lado, tampoco describe su diversidad frente a Occidente. Desde nuestro punto de vista, estamos de acuerdo, ya que nuestra idiosincrasia, si bien posee cantidad de elementos occidentales, es híbrida, tal cual lo afirma Néstor García Canclini (2001), ya que el mestizaje de los indígenas locales (que alcanzaban más de sesenta millones al momento de llegar los europeos) con los primeros colonos hispanos y lusitanos, la incorporación de más de dieciséis millones de negros procedentes de África a nuestra región (primero como esclavos), la gran inmigración proveniente de Europa (dieciséis millones), y también asiática, árabe-libanesa, turca y judía, y finalmente la propia emigración de nuestra gente en las últimas décadas del siglo $\mathrm{XX}$ a Europa y Estados Unidos así como su regreso en la primera década del siglo XXI, sin duda nos han dado una característica única como civilización.

Otro autor que ha aportado argumentos en este sentido es el psicólogo y antropólogo francés Clotaire Rapaille (2007), quien se ha valido de sus conocimientos y experiencia clínica con niños autistas para desarrollar grupos de estudio de los cuales extraer el código cultural que abre la llave de nuestro inconsciente, ya que encaja a la perfección en el correspondiente arquetipo cultural que inconscientemente nos determina. La teoría de Rapaille sostiene que nuestras decisiones como compradores o nuestras preferencias por un candidato político determinado están influenciadas por las "improntas" alojadas en el inconsciente. 
Rapacilla afirma que en realidad el conocimiento que se tiene en los diferentes países y naciones es más o menos el mismo, pero sin embargo el cambio de los códigos culturales entre distintas sociedades y naciones se deben a la manera como se fueron estructurando dichos conocimientos. Rapaille trabaja con un proceso que él denomina de descubrimiento en la identificación de los códigos culturales en la mente humana, que es otra manera de atacar el problema, como lo hemos hecho con nuestras técnicas de afloramiento de significados (París, 2012).

Asimismo, desde la óptica del comportamiento del consumidor Leon G. Schiffman y Leslie L. Kanuk (2001) afirman:

La segmentación y la diversidad del mercado son conceptos complementarios. Si no existiera un mercado diversificado, integrado por muchas personas diferentes con distintos antecedentes, países de origen, intereses, necesidades y deseos, habría pocas razones para la segmentación de mercados. La diversidad del mercado mundial hace que la segmentación del mercado sea una estrategia atractiva, factible $y$, en potencia, altamente rentable (Schiffman y Kanuk, 2001).
Sin lugar a dudas, estas son algunas de las razones, argumentos y posiciones de grandes especialistas por las cuales pensar globalmente hoy pareciera ser aún una posibilidad incierta, y para que el mundo esté poblado de consumidores globales aún falta mucho más que algunas décadas. Sin embargo, sí es cierto que en general existen algunas tendencias que podemos denominar como mundiales, sin que esto signifique que se den en todos los continentes y países al mismo tiempo.

\section{Referencia}

Baquerin de Riccitelli, M. T. (2008). Los medios: ¿aliados o enemigos del público? Derivaciones de las teorías de comunicación surgidas en los setenta. Buenos Aires: EDUCA.

García Canclini, N. (2001). Culturas hibridas, estrategias para entrar y salir de la modernidad. Buenos Aires: Paidós.

González, J.; Sánchez, J. y Salutregui, J. (2004). Personalización. Madrid: Pearson Educación.

Hitt, M. A.; Ireland, R. D. y Hoskisson, R. E. (2004). Administración 
estratégica (5. ${ }^{\mathrm{a}}$ ed.). México: Thomson.

Huntington, S. P. (2005). El choque de civilizaciones y la reconfiguración del orden mundial. Barcelona: Paidós Ibérica.

Locke, J. (1998). Compendio del ensayo sobre el entendimiento humano (trad. Rovira, R. y García Norro, J. J.). Madrid: Tecnos.

Kotler, P. (1995). Dirección de márquetin. Madrid: Prentice-Hall.

Kotler, P. (1989). Mercadotecnia (3. ${ }^{\mathrm{a}}$ ed.). México: Prentice-Hall.

Leskovec, J.; Adamic, L. A. y Huberman, B. A. (2007, mayo). The dynamics of viral márquetin. $A C M$ Transactions on the Web, 1(1). doi $>10.1145 / 1232722.1232727$.

McDaniel, C. y Gates, R. (1999). Investigación de mercados contemporánea (4. ${ }^{\mathrm{a}}$ ed.). México: Thomson.

O'Guinn, T. C.; Allen, C. T. y Semenik, R. J. (2004). Publicidad y comunicación integral de marca (3. ${ }^{\mathrm{a}}$ ed.). México: Thomson.

Ortega, E. (1987). La dirección de marketing (3. ${ }^{\mathrm{a}}$ ed.). Madrid: ESIC.
París, J. A. (2009). Márquetin esencial, un enfoque latinoamericano. Buenos Aires: Errepar.

París, J. A. (2012). La segunda miopía del marketing. Buenos Aires: Haber.

Rapaille, C. (2007). El código cultural. Bogotá: Norma.

Rojas Breu, R. (2002). Método vincular, el valor de la estrategia. Buenos Aires: Ediciones Cooperativas.

Schiffman, L. G. y Kanuk, L. (2001). Comportamiento del consumidor (7. ${ }^{a}$ ed.). México: Pearson Educación.

Solomon, M. R. (2008). Comporta-

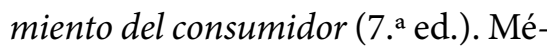
xico: Pearson Educación.

Santesmases, M.; Sánchez, F. y Kosiak, G. (2000). Marketing, conceptos y estrategias. Madrid: Pirámide.

Stanton, W. J.; Etzel, M. J. y Walker, B. J. (1999). Fundamentos de márquetin (11. a ed.). México: Ariel.

Wilson, R. F. (2009). The six simple principles of viral marketing, sin publicar. 


\section{Páginas web}

http://segmentandomercados.

blogspot.com.ar/

http://www.

healthyplace.com/blogs/

recoveringfrommentalillness/2012/04/mental-illness-

stereotypes-and-stigma/open-your-mind-logo-3/

http://www.leedstidal.org/wordpress/initiatives/past-initiatives/

http://www.márquetinpower.com/mg-dictionary.php?

http://edant.clarin.com/diario/2008/09/14/sociedad/s-01759946.htm

http://es.wikipedia.org/wiki/Dinky

http://lastendenciasdeconsumo.blogspot.com.

ar/2011/05/premiumization.html

http://www.noise-media.com/blog/cinco-campanas-de-márquetin-viral/

http://hiper-conectados.blogspot.com.ar/

http://www.puromárquetin.com/márquetin-viral

http://www.apadeshi.org.ar/cambiossocialesenlosroles.htm 